\title{
Employment based health financing does not support gender equity in universal health coverage
}

\section{Health financing and entitlement systems linked to employment can disadvantage women, argue Lavanya Vijayasingham and colleagues}

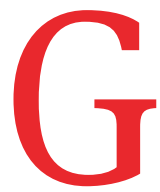

lobal commitments to improve women's access to healthcare have been made repeatedly, most recently through the sustainable development goals and the 2019 political declaration on universal health coverage. These commitments echo the vision of the 1995 Beijing Declaration to ensure that women access equitable, appropriate, affordable, and quality healthcare throughout their life. Yet, 25 years later, women remain disproportionately underserved, and their basic health needs remain unmet.

In low and middle income countries, 45 million pregnant women $(37 \%)$ have no access, or inadequate access, to antenatal care, 214 million women (13\%) who want to avoid a pregnancy are not using modern contraception, and 266000 women die from highly preventable cervical cancer $(90 \%$ of the global mortality of

\section{KEY MESSAGES}

- Progress towards universal health coverage needs financing systems that ensure women's access to equitable, appropriate, affordable, and quality healthcare throughout their lives

- Women's access to healthcare is threatened when it is linked to their employment terms, because women face more employment insecurity and transitions across their work lives, including for reproduction and unpaid care work

- Gender equitable universal health coverage reforms are needed to ensure continuity of access to high quality health benefits and financial protection during changing circumstances, such as work transitions

- Reforms should also be based on principles of accountability, non-discrimination, valuation of unpaid care work, and an evidenced based understanding of intersecting inequities the disease). ${ }^{1}$ In high income countries women forgo healthcare because of costfor example, $26 \%$ of women in Switzerland and $38 \%$ in the United States. ${ }^{23}$

In addition to the general challenges that impede universal health coverage, women's access is further constrained by health systems and the broader political economy, which mirror and reinforce restrictive gender norms, unequal power relations, and systemic discrimination. ${ }^{4}$ Women's higher unpaid care work, lower income, and often limited decision making power over household resources and their own healthcare, converge to create significant barriers to healthcare. ${ }^{4}$

These dynamics are exacerbated when healthcare financing and entitlements are linked to employment, as women experience unequal and disrupted participation in employment. Health financing mechanisms based on employment can translate gender disparities in employment into unequal healthcare access, further disadvantaging women.

\section{Employment based health financing schemes} Employment based health financing includes any form of health financing or entitlements that are linked to a person's employment status and type. Typically, pooled contributions from an employee, their employer, and/or the state are channelled to service providers for a defined set of health entitlements to the contributing individuals, and sometimes their dependants. Such schemes include mandatory contributions to national social insurance (Thailand), enrolment of informal and non-standard workers (that is, part time and casual employment) in health insurance schemes (Ghana, Vietnam), and voluntary or semi-mandatory provision of health insurance by employers to their labour market (US). Examples of health insurance provided by employers include the medical scheme for South Africa's government employees with five levels of benefit packages, in which entitlements (beyond the basic package) are linked to paid premiums ${ }^{5}$; and the policies of the US for provision of healthcare only to full time employees who work for employers with more than 50 full time staff. ${ }^{6}$

There are many criticisms of employment based health financing. Firstly, it suggests that healthcare is an employment benefit, rather than a human right. Secondly, by tying healthcare entitlements to employment status or linked contributions, it undermines the goal of universal health coverage to progressively ensure equity and continuous access to high quality healthcare. In some cases, people in higher level positions are given more healthcare entitlements or can pay higher insurance premiums to receive better quality and more expensive healthcare. Ideally, arrangements for universal health coverage should start with poorer populations who have higher unmet health needs. ${ }^{7}$ Although countries may combine employment based health financing with fully subsidised care for vulnerable groups, there is a higher risk of excluding people who fall into, or move between, different categories of entitlements, such as those who are defined by socioeconomic status, poverty lines, and pregnancy status. Lastly, as a source of health revenue, employment based health financing is unstable, fragmented, and inequitable, particularly during economic crises. ${ }^{89}$ During the covid-19 pandemic in the US, about 47.5 million people lost access to employment linked healthcare because of a job loss in the family. As of May 2020, 27 million of them were likely to remain uninsured owing to ineligibility for other health schemes. ${ }^{10}$

Universal healthcare entitlements, mandatory inclusion in national schemes, general tax contributions for resource pooling, and a move away from voluntary or contributory schemes that are linked to benefits entitlements are recommended for countering these challenges. ${ }^{11}$ There has been resistance towards this shift, however. Employment based health financing 
remains an important source of revenue, especially for low and middle income countries that need to mobilise additional domestic resources. It is also possible to use existing payroll infrastructures. ${ }^{8}$ In countries with established employment based health financing systems, the influence of existing beneficiaries often prevents reforms of these arrangements, which continue to disadvantage women. ${ }^{811}$

\section{Unequal employment terms and unpaid care work}

Gender inequalities and gaps in employment have hardly changed over the past 25 years. Globally, only $47 \%$ of women were estimated to be employed in 2019, compared with $74 \%$ of men. ${ }^{12}$ With this employment gap, and a gender pay gap of nearly $20 \%$, equality in employment has not been achieved. ${ }^{13}$

Unequal unpaid care and domestic work between men and women persists throughout the world, negatively influencing women's economic participation and opportunities. Women perform more than $80 \%$ of unpaid care work, and about 606 million women, compared with 41 million men, are full time unpaid care workers. ${ }^{13} 14$

In the formal sector, women remain overrepresented in lower level positions and receive unequal remuneration for the same role, skills, education, and experience. Wider employment gaps persist for women with children. ${ }^{14}$ The global proportion (about 27\%) of women who are managers and in professional leadership roles has hardly changed in 30 years. ${ }^{14}$ The most socioeconomically disadvantaged women are least likely to work either full time or in the formal sector. ${ }^{15}$

The informal sector provides employment for up to $90 \%$ of employed women in Africa and South Asia, and 75\% in Latin America. ${ }^{14}$ Typically, young (15-24 years) and older ( $>65$ years) women are more likely to have informal work, ${ }^{16}$ and they are concentrated in occupations with low pay, long hours, and insufficient or no social protection. ${ }^{14}$

These gender inequalities are likely to be exacerbated in the future. A changing global employment ecosystem based on technological disruptions, macroeconomic fluctuations, and dwindling levels of social and employment protection is reducing opportunities for long-term and secure employment. ${ }^{14}$ Non-standard employment arrangements, such as part time and temporary contracts, are increasing in the formal sector. ${ }^{1617}$ Similar to informal sector work, these arrangements usually lack health related social protection and job security, through their framing as "self-employment". Again, women are disproportionately affected. In Japan, where there is national employment based health financing, women are four times more likely to be on a temporary contract. ${ }^{18}$ Women in developing countries make up one in every five crowd workers, using digital platforms for task or service based income generation. ${ }^{14}$ The online "gig" economy is not expected to close gender gaps in employment or income. ${ }^{14}$

Non-standard employment arrangements are often depicted as a way to support women's engagement in paid employment by providing flexibility and enabling them to balance their economic productivity with domestic responsibilities. ${ }^{19}$ Nonstandard workers, however, typically have an income gap as high as $60 \%$ in comparison with full time workers, even in high income countries. ${ }^{17}$ During economic crises and periods of recovery, women are disproportionately represented in involuntary non-standard employment, particularly in industries or roles that are heavily dependent on women, such as the service industry. ${ }^{19}$

\section{Employment based health entitlements}

Socioeconomic and cultural factors influence women's ability to participate in paid employment throughout their life. ${ }^{15}$ Women are less likely to have long term contracts, ${ }^{20}$ and their work lives are often fragmented by transitions, owing to reproduction, care responsibilities, and voluntary and involuntary unemployment.

Employment based schemes often do not take account of these unequal trends and changes in women's employment, which often create discontinuity in coverage, benefits, and financial protection. Arrangements for universal health financing should provide continuous coverage for all people throughout their lives to meet their changing health needs. Yet, approaches to employment based health financing that visualise employment as static, rather than a trajectory, can lead to fragmented and interrupted coverage. Figure 1 draws attention to the gendered work life and women's discontinuous access to coverage, benefits, and financial protection.

Unpaid care work is not always as valued as paid work in employment based models. Some countries have separate schemes for formal sector workers and their dependants, including spouses who engage in full time unpaid care work. In Vietnam, dependants are not covered in the compulsory employment based national scheme, but they can enrol in a voluntary scheme, with fewer entitlements, that is also offered to informal sector workers. ${ }^{21}$ In Thailand, there are differences in coverage and benefits for dependants across schemes. The civil servant scheme includes coverage for members' parents, spouses, and up to two children. ${ }^{22}$ The scheme for private sector employees, however, excludes dependants, who are covered by the universal coverage scheme for the rest of the population. ${ }^{22}$

Within these systems, employment or movement across formal, informal, and non-standard roles typically changes entitlements to healthcare. In Mexico, for example, there are distinct health access schemes for formal and informal sector employees. More women than men in Mexico become unemployed, and more often. Within a single year women can move between the formal and informal sectors and between employment and unemployment..$^{23}$ These changes influence women's entitlement to high quality healthcare, which consequently affects their health. ${ }^{24}$ The same situation has also been documented in South Korea, where women are over-represented in non-standard work. ${ }^{19}$ The national health financing system distinguishes between formal sector full time, part time, non-standard, and temporary workers, and those with contracts in a single organisation for less than 24 months. ${ }^{25}$ A South Korean study found that nonstandard workers are among those who were more likely to have unmet healthcare needs due to the economic burden of care provision. $^{26}$

Women in low and middle income countries with employment based health financing schemes, such as Ghana and Kenya, tend to take part in lower income, informal, or small business work. Their income is more unpredictable and less sustainable than for men, and they are less able to make regular contributions to maintain their insurance coverage. ${ }^{27}$ In Ghana, although enrolment is mandatory for both formal and informal sectors, not all of the informal sector is enrolled. About $80 \%$ of the national workforce work in the informal sector, ${ }^{28}$ but this sector accounts for only about $30-35 \%$ of the national insurance annual membership. ${ }^{29}$ A study on women porters reports that only about half of the participants had insurance 


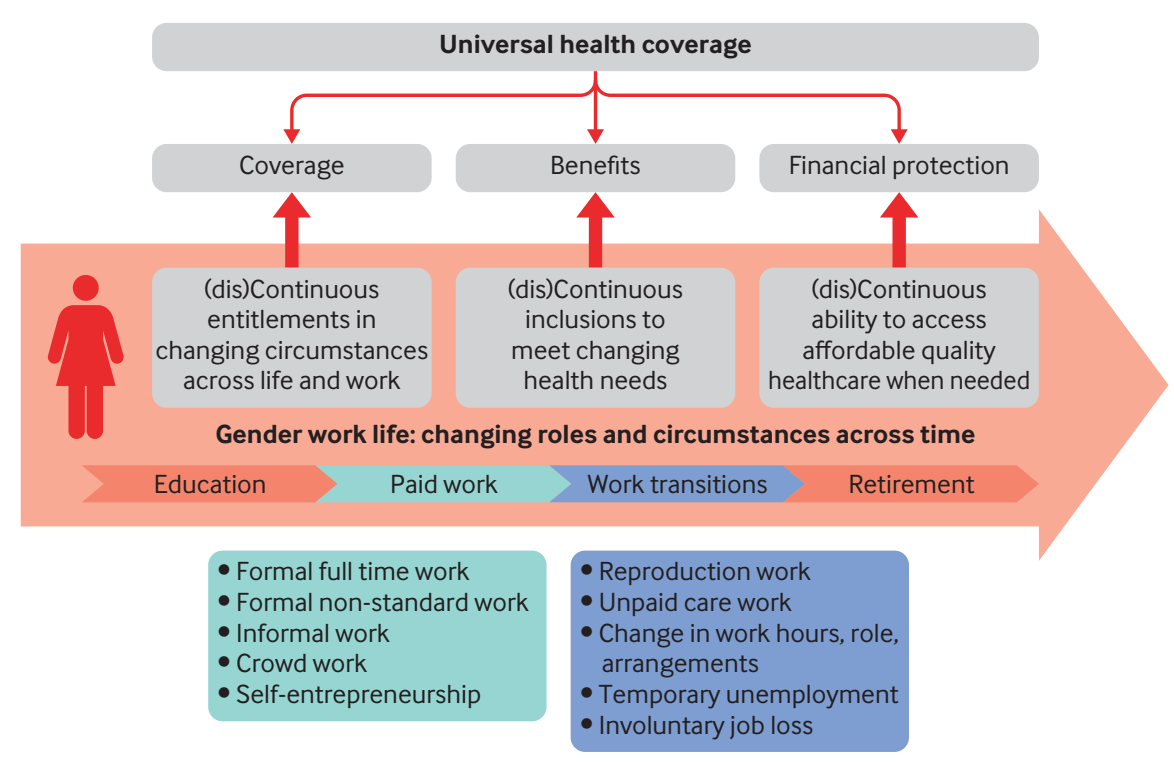

Fig 1 | Gendered work trajectories and continuous universal health coverage

and not all sought healthcare when ill or injured, primarily because they could not afford it. ${ }^{30}$ In the absence of coverage, healthcare is either foregone, or funds to pay for healthcare costs are found through informal loans or the sale of assets. ${ }^{28}$

The intersecting influence of other factors and inequities, such as chronic illness and disability, also affects women's continuous access to healthcare through these schemes. Health status and functional impairment influence changes and transitions in employment, even at milder stages of illness. ${ }^{31}$ Women with disabilities often have a dual disadvantage from their gender and disability, resulting in their over-representation in low paying, less prestigious, less autonomous, and more stressful jobs than women without disabilities, and men with disabilities. ${ }^{32}$ Additionally, a study of employed women with breast cancer in the US found that those who depended on their employer for health insurance were less likely to reduce work hours than employed married women who depended on their spouse's healthcare coverage. ${ }^{33}$ These dynamics have implications for clinical outcomes. Although social protection for illness or disability can provide a buffer against these risks, many countries with limited resources in Asia and Africa lack such schemes and systems. ${ }^{34}$

\section{How do we achieve gender equity?}

The path towards achieving universal health coverage must include gender and other equity considerations beyond socio- economic position and income. ${ }^{35}$ Transitions in employment status, income, life roles, or other life circumstances should not change an individual's access to adequate high quality and timely healthcare (fig 1). We suggest some health financing design principles to support this shift (box 1).

In countries where employment based health financing is already established or is being considered to mobilise more resources for domestic health financing, adequate safety nets must be provided to ensure equity and continuity in coverage, benefits, and financial protection. At a systems level, it is necessary to prioritise reforms towards mandatory, universal, and primarily tax-based financing approaches that separate entitlement to health benefits from contribution. Options could include pooling employee and employer contributions with non-contributory funds from government revenue.

Inherent gender based biases and discrimination must be dealt with, by valuing care and childbearing equally to productive paid work. Premiums should be regulated and affordable, and parallel non-contributory schemes should provide access to equal and high quality care. ${ }^{811}$ Existing health financing systems may also need to be redesigned to provide adequate coverage, benefits, and financial help for those who are employed through informal and non-standard work arrangements. Some countries with established schemes of employment based health financing have implemented mechanisms to deal with elements of gender inequity and discrimination. For instance, in 2012 the European Union established a ban on gender discriminatory pricing strategies within health insurance plans. ${ }^{36}$ Similarly, in the US, equal levels of premium and benefits must now be offered to all workers across all levels of positions and salaries, regardless of gender. ${ }^{37}$ Such regulations and accountability systems, built on principles of non-discrimination, are critical to promote the achievement of gender equity in health access. ${ }^{1135}$

Finally, there are considerable evidence gaps in understanding the implications of employment insecurity and transitions for women's healthcare access, especially beyond reproductive health. The health financing literature is heavily focused on systems and processes, with considerably less attention paid to people. In low and middle income countries and fragile settings, there is even less analysis and fewer interventions to deal with gender inequities, or examine how they intersect with other factors, such as age, ethnicity, religion, disability, marital status, sexual orientation, and migration status. These gaps need to be considered to inform health financing policy.

\section{Conclusion}

Many employment based health financing schemes are likely to favour men and can undermine progress towards gender equitable universal health coverage. We cannot proceed with business as usual in countries that are building their health financing systems on inequitable entitlement. Continuing on this trajectory will exacerbate gender inequities. Well designed health financing policy and systemic reforms are needed to deal with systemic gender inequality and improve healthcare access. The global urgency for these reforms is clear at this time. The gendered effect of the covid-19 crisis, including its effect on unequal care
Box 1: Equity and gender principles for guiding transformation of health financing

- Continuity, coherence, and portability across schemes

- Accountability towards universality, equity, and non-discrimination

- Valuing unpaid care and childbearing

- Updated and evidence based design and monitoring 
burdens and employment, could be the external shock and trigger needed to produce a change and the introduction of wide reaching reforms to deal with the gendered inequities of healthcare access across lifetimes.

We thank Joseph Kutzin and The BM/ reviewers for their feedback on this article.

Contributors and sources: The authors have expertise and experience on health financing and economics, public health, gender and health, employment and health, and health systems within high and low and middle income countries, including fragile and conflict affected settings, from their work in academic institutions, development organisations, and the UN system.

Competing interests: We have read and understood BMJ policy on declaration of interests and have no relevant interests to declare. The authors alone are responsible for the views expressed in this article, which do not necessarily represent the views, decisions, or policies of the institutions with which the authors are affiliated.

Provenance and peer review: Commissioned; externally peer reviewed.

This article is part of a series commissioned by The $B M J$, based on an idea from the United Nations University-International Institute for Global Health and the World Health Organization, to mark the 25th anniversary of the adoption of the 1995 Beijing Declaration and platform for action. Open access fees were paid by the UN University-International Institute for Global Health. The BMJ retained full editorial control over external peer review, editing, and decision to publish.

Lavanya Vijayasingham, postdoctoral fellow ${ }^{1}$ Veloshnee Govender, scientist ${ }^{2}$

Sophie Witter, professor of international health financing and health systems ${ }^{3}$

Michelle Remme, research lead-gender and health ${ }^{1}$ United Nations University International Institute for Global Health, Kuala Lumpur, Malaysia

${ }^{2}$ World Health Organization, Geneva, Switzerland ${ }^{3}$ Institute of Global Health and Development, Queen Margaret University, Edinburgh, UK

Correspondence to: LVijayasingham vijayasingham@unu.edu

\section{(c) (1) () OPEN ACCESS}

This is an Open Access article distributed under the terms of the Creative Commons Attribution IGO License (https://creativecommons.org/licenses/ by-nc/3.0/igo/), which permits use, distribution, and reproduction for non-commercial purposes in any medium, provided the original work is properly cited.

\section{Check for updates}

1 Starrs AM, Ezeh AC, Barker G, et al. Accelerate progress-sexual and reproductive health and rights for all: report of the Guttmacher-Lancet Commission. Lancet 2018;391:2642-92. https://www. thelancet.com/journals/lancet/article/PIIS01406736(18)30293-9/fulltext doi:10.1016/S01406736(18)30293-9
2 Commonwealth Fund. What is status of women's health? U.S. vs. 10 other countries. 2018. https:// www.commonwealthfund.org/publications/issuebriefs/2018/dec/womens-health-us-compared-tenother-countries

3 Unger J-P, De Paepe P. Commercial health care financing: the cause of U.S., Dutch, and Swiss health systems inefficiency? Int J Health Serv 2019;49:43156. doi:10.1177/0020731419847113

4 Witter S, Govender V, Ravindran TKS, Yates R. Minding the gaps: health financing, universal health coverage and gender. Health Policy Plan 2017;32(suppl_5):v4-12. doi:10.1093/ heapol/czx063

5 Goudge J, Alaba OA, Govender V, Harris B, Nxumalo N, Chersich MF. Social health insurance contributes to universal coverage in South Africa, but generates inequities: survey among members of a government employee insurance scheme. Int J Equity Health 2018;17:1. doi:10.1186/s12939-0170710-z

6 Even WE, Macpherson DA. The Affordable Care Act and the growth of involuntary part-time employment. Ind Labor Relat Rev 2018;72:955-80. doi:10.1177/0019793918796812

7 Jamison DT, Summers LH, Alleyne G, et al. Global health 2035: a world converging within a generation. Lancet 2013;382:1898-955. doi:10.1016/S01406736(13)62105-4

8 Yazbeck AS, Savedoff WD, Hsiao WC, et al. The case against labor-tax-financed social health insurance for low- and low-middle-income countries: a summary of recent research into labor-tax financing of socia health insurance in low- and low-middle-income countries. Health Aff (Millwood) 2020;39:892-7. doi:10.1377/hlthaff.2019.00874

9 Liaropoulos L, Goranitis I. Health care financing and the sustainability of health systems. Int J Equity Health 2015;14:80. doi:10.1186/s12939-0150208-5

10 Garfield R, Claxton G, Levitt L. Eligibility for ACA health coverage following job loss. Kaiser Family Foundation. 2020. https://www.kff.org/coronavirus covid-19/issue-brief/eligibility-for-aca-healthcoverage-following-job-loss/

11 Kutzin J, Yip W, Cashin C. Alternative financing strategies for universal health coverage. In: World Scientific Handbook of Global Health Economics and Public Policy. World Scientific, 2016: 267-309, https://www.worldscientific. com/doi/abs/10.1142/97898131404930005 doi:10.1142/9789813140493_0005

12 International Labor Organization. Labour force participation rate by sex and age-ILO modelled estimates, July 2019 (\%) - annual. ILOSTAT Database. 2020, https://www.ilo.org/shinyapps/bulkexplo er27/?lang=en\&segment=indicator\&id=EAP 2 W AP_SEX_AGE_RT_A

13 United Nations. Work. In: The world's women 2015: trends and statistics. 2015:87-118. https:// unstats.un.org/unsd/gender/chapter4/chapter4. html

14 Beghini V, Cattaneo U, Pozzan E. A quantum leap for gender equality: for a better future of work for all. International Labour Organization; 2019. http://www.ilo.org/global/publications/books/ WCMS_674831/lang--en/index.htm

15 Damaske S, Frech A. Women's work pathways across the life course. Demography 2016;53:365-91 doi:10.1007/s13524-016-0464-z

16 International Labour Organization. Women and men in the informal economy: a statistical picture. Switzerland; 2018. https://www.ilo.org/wcmsp5/ groups/public/---dgreports/---dcomm/documents/ publication/wcms_626831.pdf

17 International Labour Organization. Non-standard employment around the world: understanding challenges, shaping prospects. Switzerland,
2016. https://wwwilo org/wcmsp5/groups/ public/---dgreports/---dcomm/---publ/documents/ publication/wcms_534326.pdf</eref>

18 International Labour Organization. Women in nonstandard employment. Geneva Switzerland; 2017 https://www.ilo.org/wcmsp5/groups/public/---ed protect/---protrav/---travail/documents/publication/ wcms_556160.pdf </eref $>$

19 Lee J. More protection, still gendered: the effects of non-standard Employment Protection Acts on South Korean women workers. J Contemp Asia 2017;47:4665. doi:10.1080/00472336.2016.1223327

20 Menéndez M, Benach J, Muntaner C, Amable M, O'Campo P. Is precarious employment more damaging to women's health than men's?Soc Sci Med 2007;64:776-81. doi:10.1016/j. socscimed.2006.10.035

21 General Statistics Office Of Vietnam. Social insurance, health insurance and unemployment insurance by indicators and year. 2016. https://www.gso. gov.vn/SLTKE/pxweb/en/03.\%20National\%20 Accounts\%20and\%20State\%20budget/-/ E03.13.px/?rxid=5a7f4db4-634a-4023-a3dd c018a7cf951d

22 Paek SC, Meemon N, Wan TTH. Thailand's universal coverage scheme and its impact on health-seeking behavior. Springerplus. 2016. https://www.ncbi.nlm. nih.gov/pmc/articles/PMC5104696/

23 Guerra G, Gutiérrez-Calderón E, Salgado de Snyder N, Boria-Aburto VH, Martínez-Valle A, GonzálezBlock MÁ. Loss of job-related right to healthcare associated with employment turnover: challenges for the Mexican health system. BMC Health Serv Res 2018;18:457. doi:10.1186/s12913-0183283-7

24 Doubova SV Boria-Aburto VH. Guerra-Y-Guerra G, Salgado-de-Snyder VN, González-Block MÁ. Loss of job-related right to healthcare is associated with reduced quality and clinical outcomes of diabetic patients in Mexico. Int J Qual Health Care 2018;30:283-90. doi:10.1093/intahc/mzy012

25 Jeong H-S. Korea's National Health Insurance-lessons from the past three decades. Health Aff (Millwood) 2011;30:136-44. doi:10.1377/ hlthaff.2008.0816

26 Lee S-Y, Kim C-W, Kang J-H, Seo N-K. Unmet healthcare needs depending on employment status. Health Policy 2015;119:899-906. doi:10.1016/j. healthpol.2014.09.007

27 Okungu VR, McIntyre D. Does the informal sector in Kenya have financial potential to sustainably prepay for health care? Implications for financing universal health coverage in low-income settings. Health Syst Reform 2019;5:145-57.

28 Akazili J, Chatio S, Ataguba JE-0, et al. Informal workers' access to health care services: findings from a qualitative study in the Kassena-Nankana districts of Northern Ghana. BMC Int Health Hum Rights 2018;18:20. doi:10.1186/s12914-0180159-1

29 Nsiah-Boateng E, Aikins M. Trends and characteristics of enrolment in the National Health Insurance Scheme in Ghana: a quantitative analysis of longitudinal data. Glob Health Res Policy 2018;3:32. doi:10.1186/s41256-018-0087-6

30 Lattof SR. Health insurance and care-seeking behaviours of female migrants in Accra, Ghana. Health Policy Plan 2018:33:505-15. doi:10.1093/ heapol/czy012

31 Vijayasingham L, Jogulu U, Allotey P. Chronic illness and sustainable careers: how individuals with multiple sclerosis negotiate work transitions in a middle-income country. Soc SciMed 2020;245:112699. doi:10.1016/i. socscimed.2019.112699

32 Brown RL, Moloney ME. Intersectionality, work, and well-being: the effects of gender and disability. Gend Soc 2019;33:94-122. https://journals.sagepub. 
com/doi/pdf/10.1177/0891243218800636 doi:10.1177/0891243218800636.

33 Bradley CJ, Neumark D, Luo Z, Bednarek HL. Employment-contingent health insurance, illness, and labor supply of women: evidence from married women with breast cancer. Health Econ 2007:16:719-37. doi:10.1002/hec.1191

34 Walsham M, Kuper H, Banks LM, Blanchet K. Social protection for people with disabilities in Africa and Asia: a review of programmes for low- and middle- income countries. Oxf Dev Stud 2019:47:97-112. doi:10.1080/13600818.2018.1515903

35 Sen G, Govender V. Sexual and reproductive health and rights in changing health systems. Glob Public Health 2015;10:228-42. doi:10.1080/17441692.2 014.986161

36 Huang S, Salm M. The effect of a ban on genderbased pricing on risk selection in the German health insurance market. Health Econ 2020;29:3-17. doi:10.1002/hec.3958
37 Sherman BW, Gibson TB, Lynch WD, Addy C. Health care use and spending patterns vary by wage level in employer-sponsored plans. Health Aff(Millwood) 2017:36:250-7. doi:10.1377/ hlthaff.2016.1147

Cite this as: $B M J$ 2020;371:m3384

http://dx.doi.org/10.1136/bmj.m3384 